\title{
Continuum Damage Mechanics Models for the Analysis of Progressive Failure in Open-Hole Tension Laminates
}

\author{
Kyongchan Song ${ }^{1}$ \\ ATK Space Division, Hampton, VA, 23681 \\ Yingyong $\mathrm{Li}^{2}$, and Cheryl A. Rose ${ }^{3}$ \\ NASA Langley Research Center, Hampton, VA, 23681
}

\begin{abstract}
The performance of a state-of-the-art continuum damage mechanics model for interlaminar damage, coupled with a cohesive zone model for delamination is examined for failure prediction of quasi-isotropic open-hole tension laminates. Limitations of continuum representations of intra-ply damage and the effect of mesh orientation on the analysis predictions are discussed. It is shown that accurate prediction of matrix crack paths and stress redistribution after cracking requires a mesh aligned with the fiber orientation. Based on these results, an aligned mesh is proposed for analysis of the open-hole tension specimens consisting of different meshes within the individual plies, such that the element edges are aligned with the ply fiber direction. The modeling approach is assessed by comparison of analysis predictions to experimental data for specimen configurations in which failure is dominated by complex interactions between matrix cracks and delaminations. It is shown that the different failure mechanisms observed in the tests are well predicted. In addition, the modeling approach is demonstrated to predict proper trends in the effect of scaling on strength and failure mechanisms of quasi-isotropic open-hole tension laminates.
\end{abstract}

\section{Introduction}

A luminum structures for transport category aircraft have been in service for many years, and the design processes for these structures are well established. Design and certification procedures have been developed to ensure safe operations in the event of local damage or cracks in the structure. These design and certification procedures are based on the damage tolerance design philosophy that requires that any propagating crack in a structure be arrested by the next contiguous primary structural element. This design philosophy is based on linear structural analysis methods to determine the stresses in the aircraft structure and on linear elastic fracture mechanics to determine the crack growth characteristics. Extensive structural tests are usually relied upon to validate this linear structural design approach.

The introduction of laminated composite materials to aircraft structural applications has led to the development of similar linear elastic, fracture mechanics-based analysis and damage tolerant design approaches for composite structures. Numerous analytical techniques have been developed for predicting the notched strength of flat composite laminates subjected to uniaxial loads (e.g. Refs. 1-7). A comprehensive review of these models has been provided by Awerbuch and Madhukar. ${ }^{7}$ A large majority of the techniques that have been developed are semiempirical, strength-based or fracture mechanics-based theories. Their development was motivated by the need to provide simple and efficient methods for predicting the notched strength of composite structures. Most of these models have demonstrated success in predicting laminate strength in the presence of holes or notches, provided that the parameters in the model are properly determined. In general, the parameters in the models are assumed to be independent of specimen geometry. However, the parameters are strongly dependent on the material system and laminate configuration and, consequently, must be determined for each new material system and laminate stacking sequence. In addition, none of the semi-empirical fracture models address the characteristics of the crack-tip damage zone, which are laminate and material dependent, or the complex interaction of micro- and macro-failures associated

\footnotetext{
${ }^{1}$ Structural Analyst, NASA Langley Research Center, Mail Stop 188E, Senior Member, AIAA.

${ }^{2}$ Research Aerospace Engineer, Structural Mechanics and Concepts Branch, 8 West Taylor St., Mail Stop 190.

${ }^{3}$ Research Aerospace Engineer, Structural Mechanics and Concepts Branch, 8 West Taylor St., Mail Stop 190, Senior Member, AIAA.
} 
with the crack-extension process. Instead, the crack-tip damage zone is simulated as some "effective" notch-tip damage zone that is assumed to grow in a self-similar manner. In many cases, self-similar crack growth typical of a similar metal component is not observed.

The potential benefit of augmenting current design and certification processes with high-fidelity analysis methods to reduce empiricism and extensive structural testing is well recognized. Quantification of the structural fracture resistance under various loading conditions is fundamental for evaluating the residual strength and life of aircraft structures. This requirement has led to the development of progressive damage models to predict damage initiation, damage growth and ultimate strength of composite laminates. Significant progress has been achieved in developing numerical approaches and underlying constitutive models for initiation and propagation of specific damage modes. Intra-ply damage modes have been investigated primarily within the framework of Continuum Damage Mechanics (CDM), ${ }^{8,9}$ while delamination has been studied extensively using interface fracture modeling techniques such as cohesive zone models ${ }^{10}$ and virtual crack closure techniques (VCCT) ${ }^{10,11}$ Despite these advances in progressive damage modeling, recent studies ${ }^{12-15}$ have suggested that CDM models for ply failure, coupled with cohesive zone models for delamination have difficulty in accurately representing laminate failure sequences that exhibit strong coupling between transverse matrix cracking and delamination. In the CDM methodology a crack or displacement discontinuity is replaced with local volumetric stiffness degradation. As the crack opens, the stiffness degradation is such that stress should not be transferred across the crack faces. Iarve ${ }^{15}$ showed that this is not necessarily the case, and because of the spurious stress transfer, local stress redistribution is not accurately predicted in the vicinity of damage. The stress locking or spurious stress transfer observed in these studies, is mesh orientation dependent and may be alleviated by aligning the element edges with the crack direction. ${ }^{16-19}$

The present paper presents a study of the performance of a continuum damage mechanics model for intralaminar damage, coupled with a cohesive zone model for delamination, for failure prediction of quasi-isotropic open-hole tension specimens. This specimen configuration has been studied extensively, both experimentally and computationally, ${ }^{20-24}$ and represents a significant challenge for progressive damage analysis for laminate failure that is dominated by complex interactions between transverse matrix cracks and delaminations. First, limitations of stateof-the-art continuum representations of intra-ply damage, and mesh-objectivity are discussed. Particular emphasis is given to the effect of mesh orientation on the analysis predictions and the effect of mesh orientation on stress locking. Analysis predictions of a unidirectional open-hole tension specimen obtained with two meshes, a radial mesh, and a mesh with element edges aligned with the fiber orientation are presented to evaluate stress locking. Results of these analyses are then used as motivation for the development of a finite element model for the quasiisotropic laminates where individual plies are modeled with meshes that have element edges aligned with the fiber direction. Analysis predictions obtained with this mesh are then compared with experimental data to assess the modeling approach.

\section{Limitations of CDM Models}

To predict the ultimate strength of composite laminates and structures, an accurate numerical representation of all damage modes and their interactions is required. Some of the most complex damage models available ${ }^{24-27}$ rely on CDM models to represent the intralaminar damage modes (e.g., transverse matrix cracking and fiber failure) and use cohesive zone models to capture delamination between ply interfaces. However, despite advances in progressive damage modeling, recent studies (e.g., van der Meer [13]) indicate that CDM models coupled with cohesive zone models may not always represent laminate failure sequences properly. These deficiencies are particularly evident when the observed fracture mode exhibits matrix splitting and pullouts ${ }^{20}$ or when the fracture is characterized by a strong coupling between transverse matrix cracking and delamination. ${ }^{13}$

The deficiencies of the predictive capabilities can be attributed to several factors, including the incorrect prediction of the damage zone size normal to the fracture direction when using crack-band models, and the inability of local CDM models to reliably predict matrix crack paths. These limitations are mostly due to the fact that CDM models are usually implemented as "local" rather than "non-local" models ${ }^{28}$ i.e., the evolution of damage in a local CDM model is evaluated at individual integration points without consideration of the state of damage at neighboring locations, and the inability of standard finite elements to represent localized shear bands. The following discussion pertains to local implementations of CDM models, since non-local damage models are less widely used due to the difficulty in implementing them within the finite element method.

The premise of the crack-band approach for regularizing CDM models is that damage localizes into a band with a width equivalent to the element dimension. If the element size is smaller than the damage process zone, the crackband approach may not predict correctly the width of the damage zone nor the local stress field. Consequently, the 
stress redistribution resulting from damage development may be inaccurately predicted and can potentially result in inaccurate representation of damage mode interactions and failure sequences.

As a result of homogenization and damage localization, CDM models have difficulties predicting crack paths. Since homogenization eliminates the distinction between fibers and matrix, a CDM model cannot distinguish between cracks that propagate along fiber directions from those that cross fibers. ${ }^{13}$ In CDM models implemented with damage localization, the damage state at any integration point in the model depends only on the stress field at that point rather than the damage state of neighboring points. Therefore, the direction of damage evolution is driven only by the instantaneous local stress distribution. In other words, the local direction of cracking may be predicted correctly by the failure criteria, but, if the morphology of the material is not properly accounted for in the damage model, the sequence of failures that eventually defines the path of a crack at a macroscopic level may be predicted incorrectly.

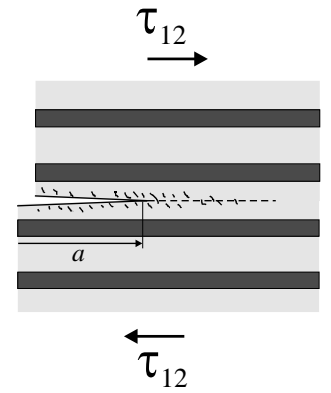

(a) Propagation of shear damage along fiber

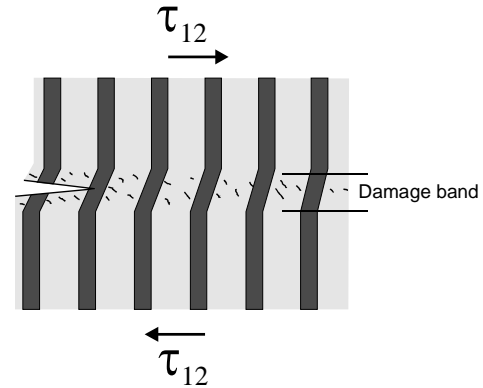

(b) Propagation across fiber direction

\section{Figure 1. Idealized propagation of shear damage (adapted from [13]).}

The potential inability of CDM models to determine the correct direction of propagation is particularly evident when the stress field is dominated by shear. Consider two different plies in a laminate with a notch and subjected to shear, as shown in Fig. 1. In both situations, the stress level required to initiate matrix micro cracks is correctly predicted by the failure criterion. Furthermore, both situations would result in an identical sequence of failures, since the stress field is identical. However, it is clearly not the same to propagate a crack in a sequence of linked micro cracks (Fig. 1a) as it is to propagate a crack band across fibers (Fig. 1b). Matrix cracking in a shear band running parallel to the fibers is a relatively brittle failure mechanism, whereas matrix cracking normal to the fibers produces a damage band that requires much more work to propagate.

The sensitivity of CDM predictions to the finite element mesh orientation also contributes to the difficulty in predicting the crack path. Although the objectivity of the solution with respect to element size is addressed with the crack-band approach $^{29}$ the predicted damage may be dependent on mesh orientation and element shape. When strain-softening constitutive models are used in a finite element simulation, damage tends to propagate along preferred directions, consisting of either element edges or element diagonals. A demonstration of the sensitivity of simulation results to mesh orientation is provided in Fig. 2 for a unidirectional compact tension specimen with fibers oriented at $90^{\circ}$ to the load direction. Results are presented for simulations obtained with a mesh oriented parallel to the fiber direction (Fig. 2a) and with an inclined mesh in front of the crack tip (Fig. 2b). The crack should propagate along the fiber direction. However, the results show directional bias, and the simulated crack band propagates in the direction of the element alignment.

The tendency for damage to localize along mesh lines can be partially attributed to shear locking. ${ }^{17}$ In the CDM methodology, a crack or displacement discontinuity is represented by a degradation of the corresponding terms in the constitutive stiffness. As the crack opens, the stiffness degradation is such that stress should not be transferred across the crack faces. However, unloading may not occur due to in-plane shear locking. Shear locking here refers to inappropriate shear stress transfer across a widely open smeared crack, which occurs when an element cannot shear without inducing tensile strains. In a ply with orthotropic properties, a matrix crack should be represented by setting the transverse shear modulus $G_{12}$ and the transverse Young's modulus $E_{22}$ to zero. However, quadrilateral elements have been shown to exhibit coupling between the $\gamma_{12}$ and $\varepsilon_{11}$ strains unless the element edges are aligned with the softening band or are oriented at 45 degrees to the band. ${ }^{17}$ Furthermore, the tendency of the element to lock is dependent on the order of integration of the element: fully integrated elements are more susceptible to pathological in-plane shear locking than reduced-integration elements. 


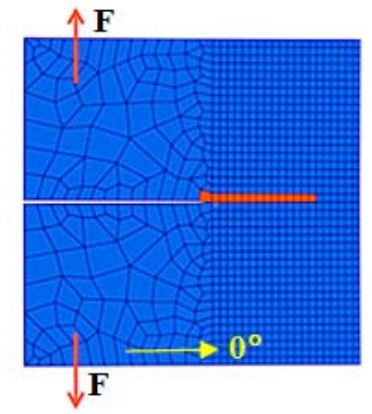

(a) Mesh aligned with crack direction

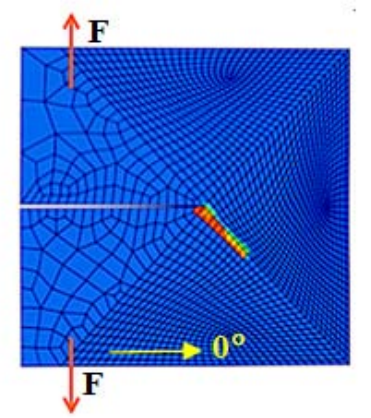

(b) Mesh inclined to crack direction

Figure 2. Effect of mesh orientation on crack path in a unidirectional compact tension specimen.

Shear stress transfer across an open smeared crack caused by shear locking can result in inaccurate prediction of stress redistribution after damage development. Iarve ${ }^{15}$ demonstrated shear locking for a simple case of a unidirectional $\left[0_{8}\right]$ graphite-epoxy open-hole tension specimen. Experiments show that this specimen exhibits splitting cracks parallel to the load and tangent to the hole. Splitting near holes and notches reduces the stress concentration, so predicting their effect is essential to obtain the ultimate strength with any accuracy. Iarve's progressive damage analyses were conducted using a radial-type mesh pattern with different levels of mesh refinement, where a radial mesh consists of the typical pattern of elements radiating from a circular hole and ending at a rectangular boundary. It was demonstrated that it is not possible to predict the stress relaxation with a radial mesh due to longitudinal splitting unless the fiber-direction modulus, $E_{11}$, is also set to zero.

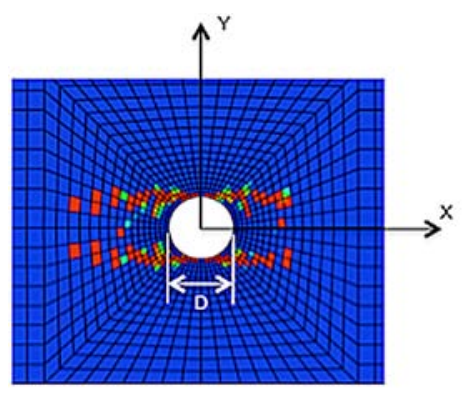

(a) Radial Mesh

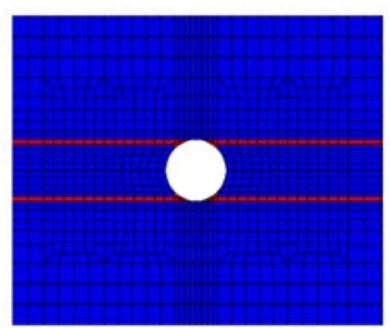

(b) Aligned Mesh

Figure 3. Splitting damage predicted using a radial mesh and an aligned mesh.

When damage localizes and a fracture path is known a priori, a relatively simple approach to circumvent some of the limitations of CDM noted above consists of aligning the mesh with the direction of fracture. ${ }^{19}$ Mesh alignment can be used to force a matrix crack to localize along the fiber direction. The benefit of mesh alignment is demonstrated below for an open-hole tension specimen. Predictions were obtained for an $\left[0_{8}\right]$ IM7-8552 laminate using the continuum damage mechanics model provided within the ABAQUS ${ }^{8}$ finite element code. ${ }^{32}$ Each ply was modeled using quadrilateral reduced integration shell elements, S4R, to minimize the tendency for locking. Analyses were obtained using a radial mesh and an aligned mesh, as shown in Fig. 3. The loading direction and fiber direction are parallel to the $X$-axis.

The damage zones predicted in the region of the hole at the peak load, using the radial and aligned meshes are shown in Fig. 3. The results indicate that both models predict longitudinal splitting tangent to the hole. The load versus end-displacement response obtained with the two models is shown in Fig. 4a. The radial mesh model predicts failure of the specimen at 77 kips compared to the peak load of 116 kips predicted by the model with the aligned mesh. The peak load predicted with the radial mesh was significantly lower than the predicted peak load with the aligned mesh. This is probably due to the inability of rotated elements with the radial mesh to represent shearing along the axial split. The axial stress, $\sigma_{11}$, normalized by the axial stress at the loading end of specimen, $\sigma_{x}$, obtained from the radial mesh and the aligned mesh at 77kips is shown as a function of distance from the hole edge (Y- 


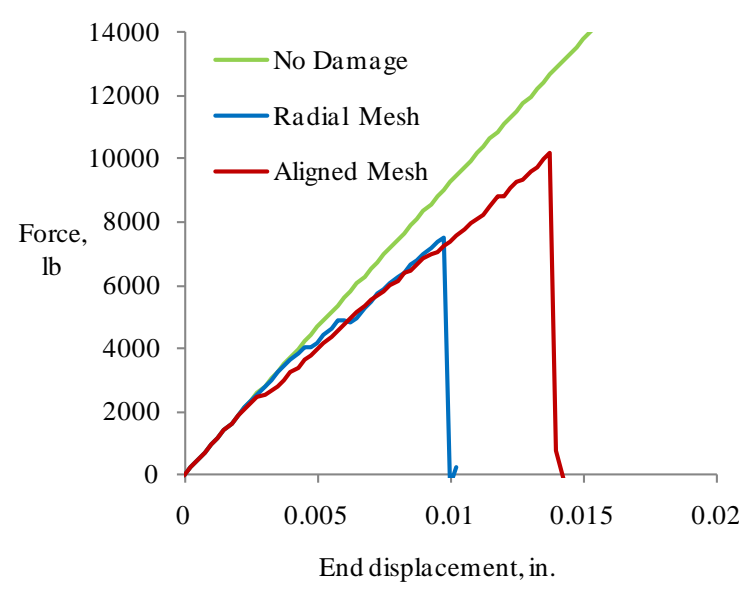

(a) Load versus end-displacement

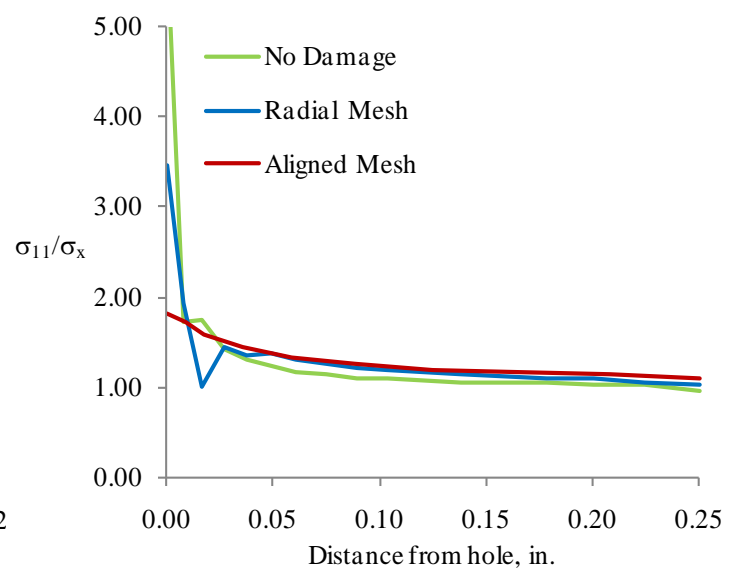

(b) Normalized axial stress distribution

Figure 4. Effect of mesh type on predicted ultimate failure and fiber-stress relaxation due to splitting in a $[0]_{8}$ laminate.

direction) in Fig. 4b to demonstrate effect of the mesh orientation on the stress distribution at the hole. The results obtained with the aligned mesh indicate that the stress concentration at the hole is nearly eliminated as a consequence of the split, as expected. The results obtained using the radial mesh show insufficient stress relaxation at the edge of the hole, indicating that damaged elements transfer shear load across the damaged band even though the matrix-dependent moduli $G_{12}$ and $E_{22}$ have been set to zero.

\section{Problem Description and Analysis Procedure}

\section{A. Open-Hole Tension Test - Experimental Summary}

The open-hole tension (OHT) specimen was recently studied, both experimentally and computationally by Hallett and Green et al. ${ }^{20,21}$ A schematic of the specimens considered is shown in Fig. 5. Specimens were fabricated from IM7/8552 graphite-epoxy and had a quasi-isotropic stacking sequence. Three-dimensional scaling, with plylevel and sublaminate-level approaches to through-the-thickness scaling, was examined to determine size effects in laminate failure. Ply-level scaled specimens are considered in the present study. Ply-level scaled specimens were fabricated by blocking multiple plies with the same orientation together, thereby increasing the effective ply thickness. Four thicknesses were considered with the stacking sequence $\left[45_{m} / 90_{m} /-45_{m} / 0_{m}\right]_{s}$ and with $m=[1,2,4,8]$. The plate width to hole diameter ratio, w/d was kept constant at a value of 5 , and the length to hole diameter ratio, $l / d$, was equal to 20 .

The experimental data indicate that the failure progression and the mode of laminate failure are dependent on the laminate layup (stacking sequence and ply thicknesses) and that the scaling of strength with respect to size is dependent on the type of failure. Sub-critical damage that develops at relatively low loads prior to the ultimate

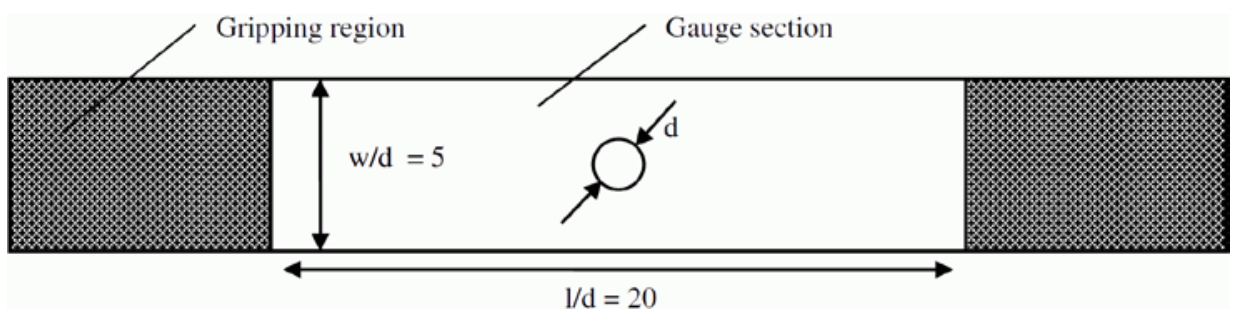

Figure 5. Specimen configuration. ${ }^{20}$ 
failure of the OHT specimens was determined to have a significant impact on the ultimate failure load and the failure mode. The progressive damage development in the OHT specimens was reported in detail by Hallet et al., ${ }^{21}$ and is summarized here. For all geometries, there were several damage processes that evolved in a coupled manner before final failure. The first failure observed in the tests was matrix cracking in the $90^{\circ}$ plies at the free edge of the hole. These cracks were followed by the development of matrix cracks in the off-axis plies and in the $0^{\circ}$ plies at the free edge of the hole, typically at tangent locations. Dominant cracks or splits developed in the surface $45^{\circ}$ plies and in the $0^{\circ}$ plies. The cracks in the $-45^{\circ}$ and $90^{\circ}$ plies were more distributed and developed along the $45^{\circ}$ and $0^{\circ}$ splits. With continued loading, a triangular delamination developed at the hole edge between the surface $45^{\circ}$ and the adjacent $90^{\circ}$ ply. The splits also increased in length with continued loading until the split in the $45^{\circ}$ surface plies reached the free edge. At that point, another triangular delamination region formed at the specimen free edge between the $45^{\circ}$ split and a crack in the $90^{\circ}$ ply. The damage at the specimen free edge then linked up with the damage at the hole edge, and propagated through the thickness of the laminate, until reaching the $0^{\circ}$ ply.

The extent of the sub-critical damage development described above is dependent on the laminate geometry and significantly influences the laminate failure mode. Three laminate failure modes were identified and were classified as either brittle, pull-out or delamination. For small values of blocked plies, the brittle failure mode was observed, in which little sub-critical damage develops and is dominated by fiber failure. For increasing numbers of blocked plies, a transition to a pull-out failure mode and then to a delamination failure mode was observed. The pull-out failure mode is characterized by sub-critical damage that propagates across the width of the specimen, allowing the off-axis plies to separate from each other, without fiber failure. The delamination failure mode is characterized by significant sub-critical damage development in the form of transverse matrix cracks in the individual plies and delaminations that link-up prior to ultimate failure. The three failure modes are shown in Fig. 6.

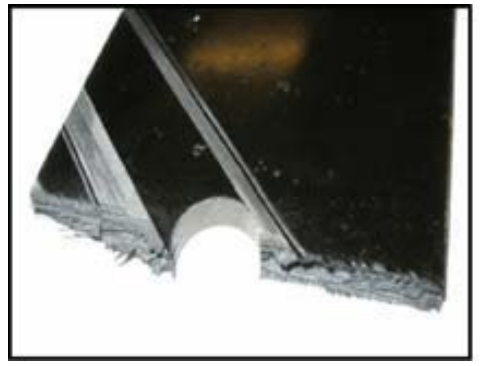

(a) Brittle failure mode

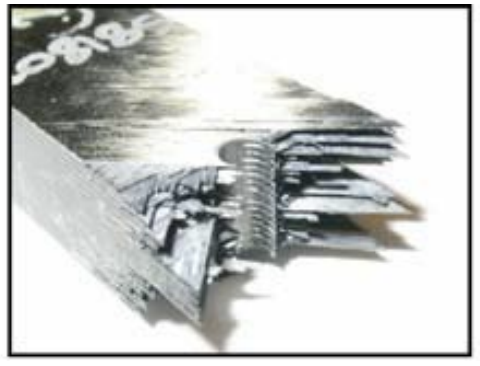

(b) Pull-out failure mode

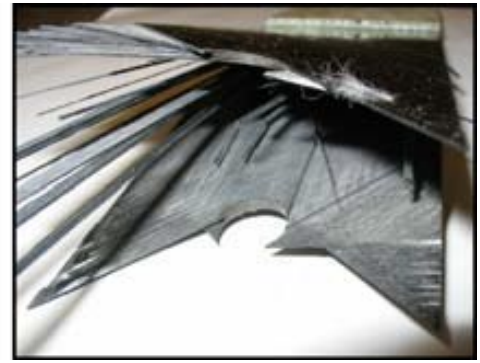

(c) Delamination failure mode

\section{Figure 6. Open-hole tension specimen failure modes. ${ }^{20}$}

\section{B. Progressive Damage Analysis}

Progressive damage analysis for the open hole tension specimens was conducted in ABAQUS explicit using the continuum damage mechanics model implemented in $A B A Q U S^{30}$ to represent the intralaminar damage modes (e.g., transverse matrix cracking and fiber failure), and cohesive elements to capture delamination at ply interfaces. The intralaminar and interlaminar damage models implemented in ABAQUS are briefly described below.

\section{Intralaminar Damage}

The continuum damage mechanics model implemented in ABAQUS to simulate intralaminar damage is available for elements that have a plane stress formulation, and is intended for the prediction of elastic-brittle materials that show no appreciable plastic deformation before failure. Four failure modes including fiber tension, fiber compression, matrix tension, and matrix compression are considered and are represented separately. Initiation of damage, which refers to the onset of damage at a material point is based on Hashin's theory. ${ }^{31}$ The Hashin Criteria for the four different failure modes are described in Equations (1) - (4) as follows:

Fiber tension $\left(\sigma_{11} \geq 0\right)$

$$
F_{f}^{t}=\left(\frac{\sigma_{11}}{X^{T}}\right)^{2}+\alpha\left(\frac{\tau_{12}}{S^{L}}\right)^{2}
$$


Fiber compression $\left(\sigma_{11} \leq 0\right)$

$$
F_{f}^{c}=\left(\frac{\sigma_{11}}{X^{C}}\right)^{2}
$$

Matrix tension $\left(\sigma_{22} \geq 0\right)$

$$
F_{m}^{t}=\left(\frac{\sigma_{22}}{Y^{T}}\right)^{2}+\left(\frac{\tau_{12}}{S^{L}}\right)^{2}
$$$$
F_{m}^{c}=\left(\frac{\sigma_{22}}{2 S^{T}}\right)^{2}+\left[\left(\frac{Y^{C}}{2 S^{T}}\right)^{2}-1\right] \frac{\sigma_{22}}{Y^{C}}+\left(\frac{\tau_{12}}{S^{L}}\right)^{2}
$$

In the above equations, $\sigma_{i j}$ are the components of the effective stress tensor, and $X^{T}$ and $X^{C}$ are the longitudinal tensile and compressive strengths, $Y^{T}$ and $Y^{C}$ are the tensile and compressive strengths in the matrix direction, and $S^{L}$ and $S^{T}$ denote the longitudinal and transverse shear strengths. The coefficient $\alpha$ in Equation (1) determines the contribution of the shear stress to the initiation of fiber tensile failure. Once a damage initiation function is satisfied, the associated damage variable is different from zero and further loading will cause degradation of the material stiffness coefficients. The stiffness matrix of a damaged ply is defined as

$$
\begin{gathered}
\sigma=C_{d} \varepsilon \\
C_{d}=\frac{1}{D}\left[\begin{array}{ccc}
\left(1-d_{f}\right) E_{11} & \left(1-d_{f}\right)\left(1-d_{m}\right) v_{21} E_{22} & 0 \\
\left(1-d_{f}\right)\left(1-d_{m}\right) v_{12} E_{22} & \left(1-d_{m}\right) E_{22} & 0 \\
0 & 0 & \left(1-d_{s}\right) G_{12} D
\end{array}\right]
\end{gathered}
$$

where $D=1-\left(1-d_{f}\right)\left(1-d_{m}\right) v_{12} v_{21} d_{f}$ and $d_{f}$ is the damage variable associated with fiber fracture, and $d_{m}$, and $d_{s}$, are damage variables associated with matrix failure. The damage evolution laws for the damage variables are defined in terms of the fracture energy dissipated during the damage process. Methods for determining the fracture energies are provided in Ref [32]. The damage evolution laws need to ensure that the computed energy dissipated is independent of the mesh. To do so, the energy dissipated for each damage mechanism is regularized using the crackband model. ${ }^{29}$

\section{Interlaminar Damage}

Interlaminar damage is simulated by placing ABAQUS cohesive elements, COH3D8, at potential delamination interfaces. The constitutive response of the cohesive elements in single-mode loading is defined by a bi-linear traction-separation law. Initially the crack is assumed to be elastic, and the crack closing forces are related to the interfacial displacement jump, $\delta_{\text {coh }}$ by a high penalty stiffness $K$. If the interfacial displacement jump exceeds a critical value, $\delta_{i}$, damage is assumed to have initiated, and the stiffness of the cohesive element is degraded. The crack closing forces are assumed to soften linearly such that the area under the traction-displacement curve is equal to the fracture toughness, $G_{c}$. Complete separation is achieved when the displacement jump exceeds $\delta_{f}$. For singlemode loading, the bi-linear cohesive law can be expressed as:

$$
\sigma=\left\{\begin{array}{c}
K \delta, \quad \delta<\delta_{i} \\
\left(1-d^{*}\right) K \delta, \quad \delta_{i} \leq \delta<\delta_{f}
\end{array}\right.
$$

where the damage variable $d^{*}$ is a function of the displacement jump and accounts for the reduction in the loadcarrying ability of the material as a result of damage. The damage variable $d^{*}$ has a value of zero when the interface is undamaged, and a value of one when the interface is fully fractured.

For crack growth under mixed-mode loading, ABAQUS provides options for defining the point of damage initiation and the critical energy release rate for damage evolution. In all of the analysis presented herein, the onset of delamination is determined based on the quadratic interaction criterion 
Table 1. IM7/8552 Material Properties

\begin{tabular}{|c|c|c|c|c|c|c|c|c|}
\hline $\begin{array}{c}\mathrm{E}_{11} \\
(\mathrm{msi})\end{array}$ & $\begin{array}{c}E_{22} \\
(\mathrm{msi})\end{array}$ & $\begin{array}{c}\mathrm{G}_{12} \\
(\mathrm{msi})\end{array}$ & $v_{12}$ & $\begin{array}{c}\mathrm{X}_{\mathrm{t}} \\
(\mathrm{msi})\end{array}$ & $\begin{array}{c}\mathrm{X}_{\mathrm{c}} \\
\text { (msi) }\end{array}$ & $\begin{array}{c}\mathrm{Y}_{\mathrm{t}} \\
(\mathrm{msi})\end{array}$ & $\begin{array}{c}\mathrm{Y}_{\mathrm{c}} \\
(\mathrm{msi})\end{array}$ & $\begin{array}{c}\mathrm{S} \\
(\mathrm{msi})\end{array}$ \\
\hline 24.85 & 1.316 & 0.765 & 0.32 & 0.3373 & 0.1740 & 0.0090 & 0.02897 & 0.0134 \\
\hline
\end{tabular}

where the Macaulay bracket $<>$ indicates that a compressive normal stress $\sigma_{z z}$ does not contribute to the damage initiation, and $T$ and $S$ are the interfacial normal and shear strengths, respectively. The shear strengths in the two orthogonal directions are assumed to be equal. The critical fracture energy is determined from the Benzeggaagh and Kenane (BK) criterion $^{33}$

$$
G_{c}=G_{I C}+\left(G_{I I C}+G_{I C}\right)\left(\frac{G_{\text {Shear }}}{G_{T}}\right)^{\eta}
$$

where $\eta$ is the BK material parameter, $G_{\text {shear }}=G_{I I}+G_{I I I}, G_{T}=G_{I}+G_{I I}+G_{I I I}$, and $G_{I C}$ and $G_{I I C}$ are the critical fracture toughness values for pure Mode I and Mode II fracture, respectively.

\section{Finite Element Models}

Analyses were conducted for a subset of the ply-level scaled specimens tested by Winsom et al. and include specimens with $d=1 / 8,1 / 4$, and $1 / 2$ inches and with $m=1,2$ and 4 . Mechanical properties for the IM7/8552 graphite-epoxy material are taken from Camahno, ${ }^{24}$ and are provided in Table 1 . Fracture toughness parameters for the fiber and matrix failure modes are provided in Table $2{ }^{24}$ The damage parameters provided for the matrix are used for both matrix damage and for interlaminar damage. To account for the in-situ effect on the intralaminar damage, the in-situ transverse tensile and shear strengths are determined using the unidirectional strength properties and the formulas proposed by Camanho et al. ${ }^{34}$ The in-situ strengths take into account the ply thickness and the difference in constraint effects on an inner or outer ply. In-situ strength properties used in the analyses are provided in Table 3. In addition, the initial elastic stiffness for the interface cohesive law is taken to be $K=8.0 \times 10^{8} \mathrm{psi} / \mathrm{in}$.

Table 2. IM7/8552 Fracture Energies for Longitudinal and Transverse Fracture (lb-in/in ${ }^{2}$ )

\begin{tabular}{cccc}
$\mathrm{G}_{\mathrm{IC}+}$ (fiber) & $\mathrm{G}_{\mathrm{IC}-}$ (fiber) & $\mathrm{G}_{\mathrm{IC}}$ (matrix) & $\mathrm{G}_{\mathrm{IIC}}$ (matrix) \\
\hline \hline 461.5 & 601.9 & 1.571 & 4.462 \\
\hline \hline
\end{tabular}

Finite element models were developed to simulate coupled interlaminar and intralaminar damage progression. The thickness of each model was represented by seven sublaminates, with a cohesive element layer of zero thickness between them. Each sublaminate represents a group of blocked plies in a laminate. Two mesh types were used for the in-plane discretization to demonstrate the effect of mesh orientation on the predicted development of damage

Table 3. Calculated In-situ Strengths for IM7-8552

\begin{tabular}{cccc}
\hline \hline & Orientation, thickness (in) & $\begin{array}{c}\mathrm{Y}_{\mathrm{t}} \\
(\mathrm{psi})\end{array}$ & $\begin{array}{c}\mathrm{S} \\
(\mathrm{psi})\end{array}$ \\
\hline \hline Surface ply & $45^{\circ}, 0.02$ & $7.31 \times 10^{3}$ & $9.71 \times 10^{3}$ \\
Inner ply & $90^{\circ} /-45^{\circ}, 0.02$ & $1.43 \times 10^{4}$ & $1.66 \times 10^{4}$ \\
Inner ply & $0^{\circ}, 0.04$ & $1.43 \times 10^{4}$ & $1.66 \times 10^{4}$ \\
\hline \hline
\end{tabular}



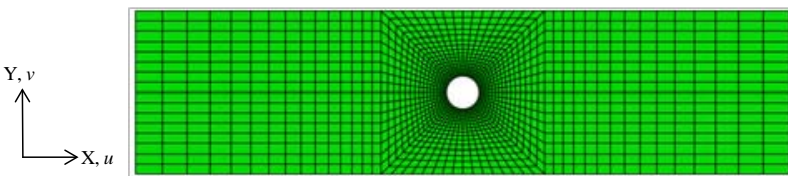

(a) In-plane discretization

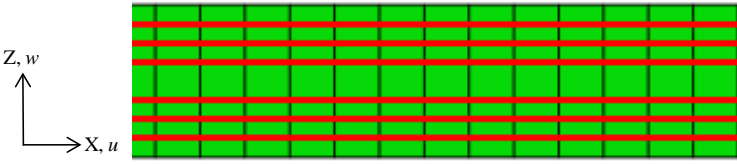

(b) Through-thickness discretization

Figure 7. Finite element model, radial mesh.

and specimen failure. The first mesh, referred to as a radial mesh, is shown in Fig. 7. The radial mesh was generated by aligning element edges along radial lines around the hole, and all plies were modeled with the same mesh. The cohesive elements between the plies were connected to the structural ply elements by coincident nodes. A second mesh, referred to as the aligned mesh, was also used. The aligned mesh consisted of different meshes within the individual plies, such that the element edges aligned with the ply fiber direction. This modeling approach is proposed on the basis that transverse matrix cracks in individual plies propagate along the fiber direction. The aligned mesh can potentially eliminate spurious stress transfer across crack faces that would otherwise occur, as has been demonstrated by Jirásek. ${ }^{16-18}$ Individual finite element discretizations for each ply, and the cohesive element layer discretization are shown in Fig. 8 for the aligned mesh. Tie constraints were used to connect the ply structural elements with the cohesive layer elements. In-plane mesh refinement was used to provide elements with side lengths approximately equal to 0.01 inches (approximately $0.3 \mathrm{~mm}$ ) in a region near the hole for the specimens with the smallest in-plane dimensions. This mesh density has been recommended to accurately represent the process zone for simulating delamination propagation ${ }^{10}$ and for modeling progressive intralaminar damage. For the larger specimens, the elements were scaled by the in-plane scale factor, giving element edge lengths near the hole equal to 0.02 inches and 0.04 inches, for the specimens with $1 / 4$-inch and $1 / 2$-inch diameter holes, respectively. For these specimens the element edge lengths are larger than recommended, but this mesh density was retained to keep the computational requirements manageable. A detailed study of the effect of element size on the predictions has not been conducted, and will be addressed in future studies.

Each sublaminate or blocked-ply group was modeled using the ABAQUS quadrilateral continuum shell element, SC8R. The SC8R continuum shell element is an 8-node, quadrilateral, first-order interpolation shell element with reduced integration and 3 degrees of freedom per node. Blocked plies were numerically represented by a single element through the thickness of the ply block. The cohesive layers between plies were modeled using the ABAQUS COH3D8 zero-thickness cohesive elements. The boundary conditions at the left end of the specimen were fully clamped $(u, v, w=0)$. At the right end of the specimen, the transverse displacements, $v$ and $w$ were constrained and a uniform axial displacement, $u$, was prescribed. In the explicit analysis, a final displacement, and a simulation

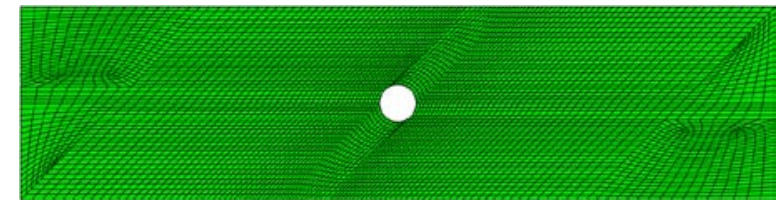

$45^{\circ}$ layer mesh

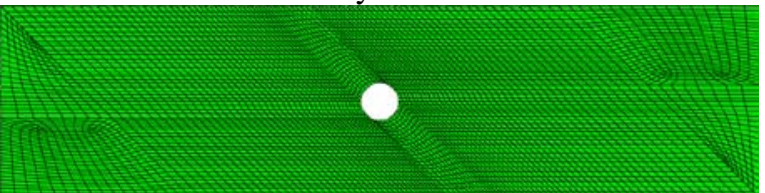

$-45^{\circ}$ layer mesh

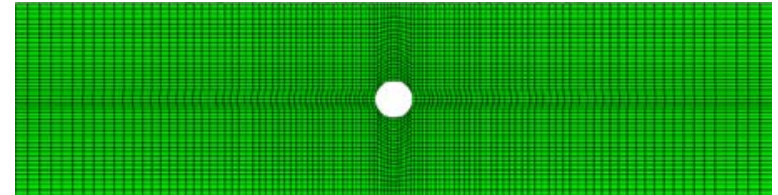

$90^{\circ}$ layer mesh

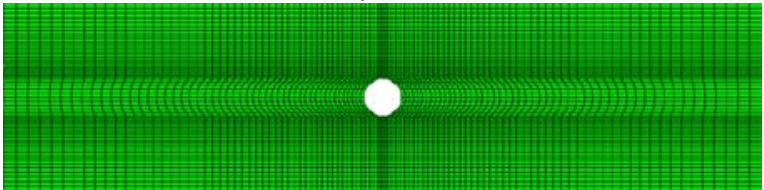

$0^{\circ}$ layer mesh

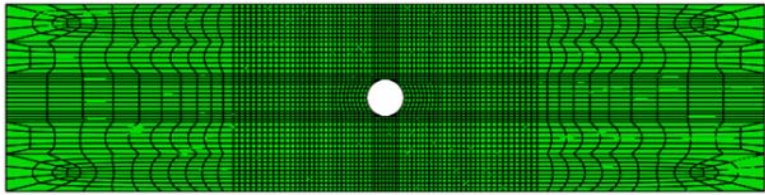

Cohesive element layer mesh

Figure 8. Finite element model, aligned mesh. 


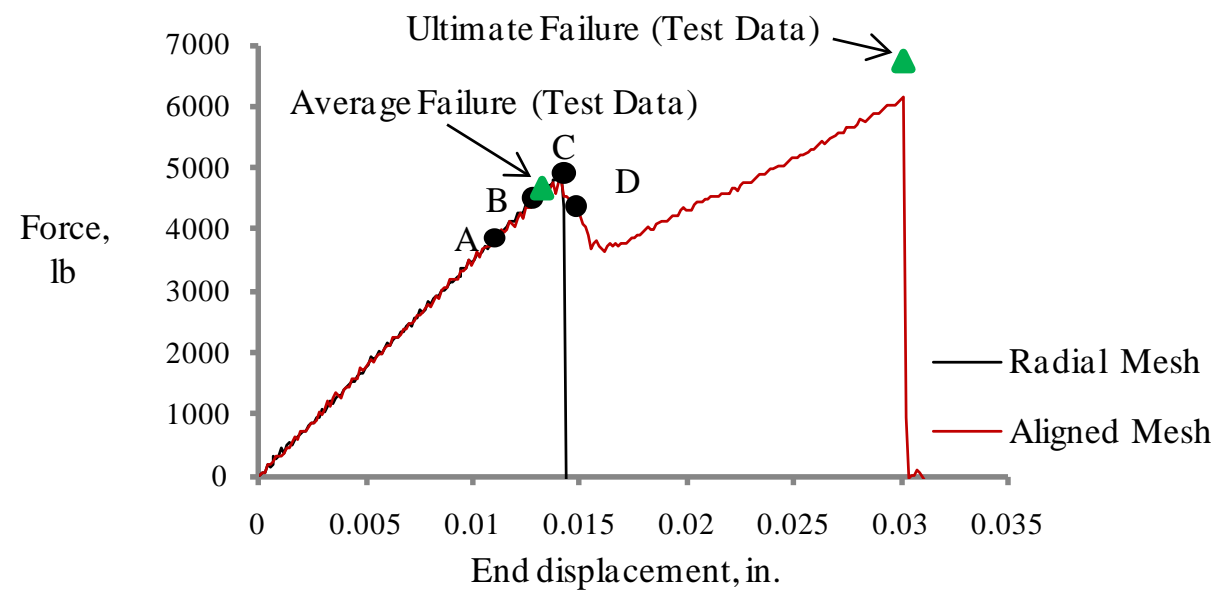

Figure 9. Predicted load versus displacement response obtained with the radial mesh and the aligned mesh, $d=1 / 8$-inch, $m=4$.

period are prescribed, to give a displacement loading rate. For computational efficiency, the displacement rate was between 2.0 (in./sec.) and 3.5 (in./sec.) in all analyses. A mass density of $1.5 \times 10^{-3} \mathrm{lb}_{\mathrm{in}}{ }^{3}$ was used for the ply structural elements, and the cohesive elements were assumed to be weightless. During the simulations, the kinetic energy was monitored to ensure that the kinetic energy did not exceed $5 \%$ of the total strain energy to ensure that significant dynamic effects were not introduced into the simulations by using relatively short total loading times.

\section{Results}

Numerical results of the progressive damage analysis of the quasi-isotropic open-hole specimens are presented in this section. First, damage evolution and ultimate failure results predicted with the radial and aligned meshes are presented and compared with experimental observations. Second, the predicted effect of in-plane (2D) scaling and through-thickness scaling (1D) on the laminate strength and failure mode is compared with experimental data. Discrepancies between the analysis predictions and the experimental results are described, and possible explanations for the discrepancies are provided.

\section{A. Radial Mesh and Aligned Mesh Predictions, $d=1 / 8$-inch, $m=4$}

Predicted load versus deflection responses obtained with the radial mesh and the aligned mesh for the specimen with a 1/8-inch diameter hole and $m=4$ are shown in Fig. 9. Test results obtained by Green, Wisnom and Hallett, ${ }^{20,21}$ indicate that this specimen configuration fails in the delamination failure mode. For this mode, two failure stress levels were reported: an average failure stress and an ultimate failure stress. The average failure stress was defined as the stress level at which there was a significant load drop ( $5 \%$ or greater) in the load-displacement response. Table 4 shows the average failure and ultimate failure stress results obtained with the two meshes, along with the experimental data. As indicated in Fig. 9 and Table 4, results obtained with the aligned mesh are consistent with the experimental observations. A significant load drop is observed in the load versus displacement response

Table 4. Experimental and Predicted Average and Ultimate Failure Stresses for Specimen with $d=1 / 8$ inch, $m=4$

\begin{tabular}{lccc}
\hline \hline & Experimental Results & Radial Mesh & Aligned Mesh \\
Average Failure Stress, ksi & 39.9 & 49.2 & 48.2 \\
Ultimate Failure Stress, ksi & 65.3 & 49.2 & 60.7 \\
\hline \hline
\end{tabular}




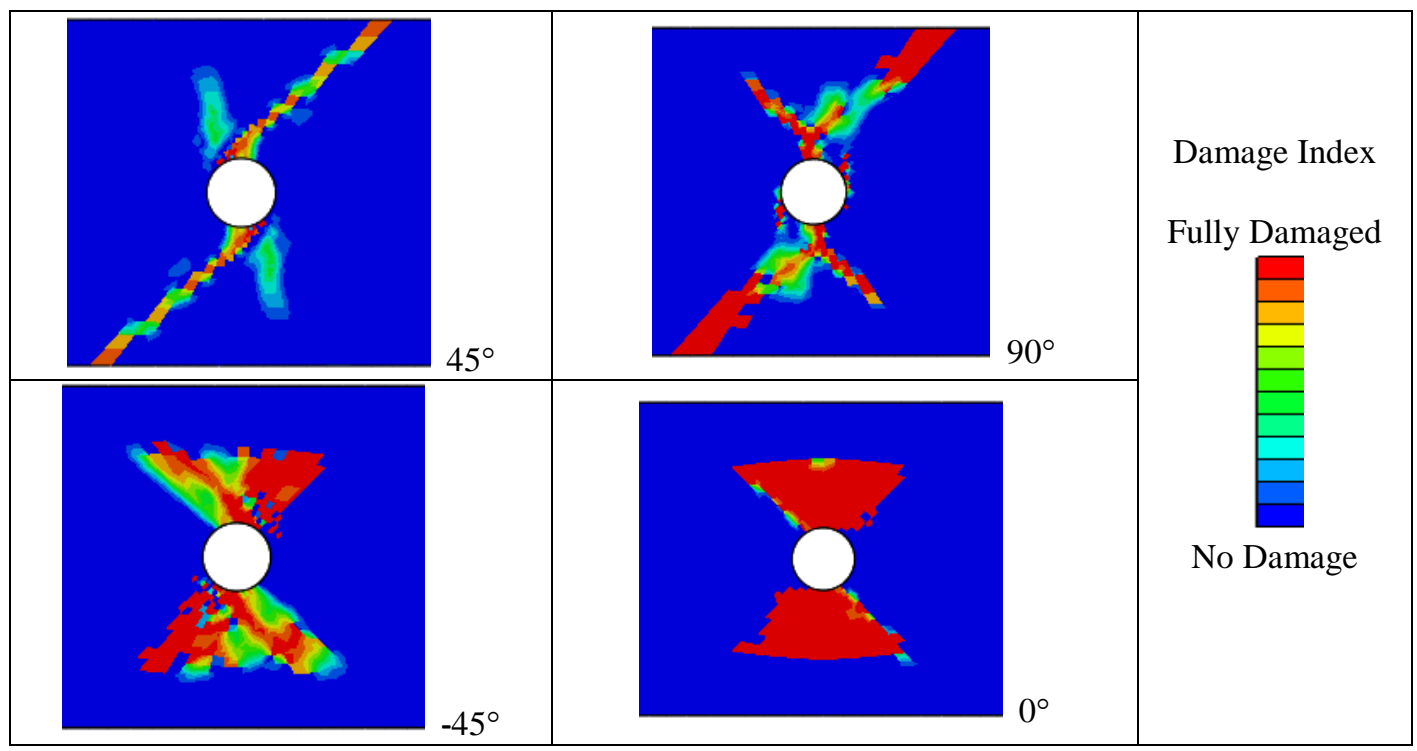

Figure 10. Matrix damage predictions obtained with the radial mesh just beyond peak load, $d=1 / 8$ inch, $m=4$.

curve (C to D), corresponding to extensive delamination between the $-45^{\circ}$ and $0^{\circ}$ plies, prior to reaching the ultimate load. The predicted average failure stress is $20 \%$ higher than observed in the tests, and the predicted ultimate stress is approximately $10 \%$ higher than obtained in the tests (Table 4). The radial mesh, on the other hand fails to predict the delamination failure mechanism, and ultimate failure is predicted early. The predicted load versus displacement response obtained with the radial mesh is linear up to ultimate failure, and the ultimate load is approximately $25 \%$ lower than the ultimate load obtained in the tests.

Matrix damage predictions in the individual plies obtained from the radial mesh at the peak load are shown in Fig. 10. At the peak load, some axial-splitting damage has developed in the $0^{\circ}$ layer at the hole edge. The predicted matrix damage trajectories in the $45^{\circ}$ and $90^{\circ}$ plies are very similar, and very little delamination develops between these plies. Fairly significant delaminations develop at the 90/-45 interface and at the -45/0 interface (not shown). However, significant stress relief at the hole edge is not predicted, and the specimen is predicted to fail prematurely as a result of fiber failure in the $0^{\circ}$ ply.

Damage predictions obtained with the aligned mesh at selected points in the load-displacement response are provided in Fig. 11. The analysis results indicate that matrix cracking develops in all plies at low load levels (Point A, $3854 \mathrm{lb}$ ). With increasing load, significant progressive growth of delaminations begins to form beyond the holeedge (Point B, $4496 \mathrm{lb}$ ). With further increase in load, the $45^{\circ}$ surface cracks propagate to the free edge, and a delamination develops at the 45/90 interface between the laminate free edges and the $45^{\circ}$ cracks. The edge delaminations then link-up with the delaminations around the edge of the hole, forming a delamination over the entire width of the specimen (Point C, $4802 \mathrm{lb}$ ). The damage is then able to propagate through the laminate thickness, and a major delamination between the $-45^{\circ}$ ply and the $0^{\circ}$ ply develops (Point D, $4474 \mathrm{lb}$ ). The delamination propagates rapidly throughout the specimen, leading to nearly complete separation of the $-45^{\circ}$ and $0^{\circ}$ layers and the load drop shown in Fig. 9. In addition, extensive delamination between the $90^{\circ}$ and $45^{\circ}$ layers, bounded by cracking in the off-axis plies is observed. With continued loading after the load drop, the axial splits propagate to the specimen ends and the interface between the $-45^{\circ}$ and $0^{\circ}$ plies completely delaminates. At the ultimate stress, delamination failure of the specimen is predicted, with fiber failure in the 0-degree ply.

Comparison of damage predictions with typical X-Ray/CT (Computed Tomography) and ultrasonic images taken from interrupted tests of specimens conducted by the authors are provided in Figs. 12 and 13 for a specimen with a 1/8-inch diameter hole, and $m=4$. The test specimens were incorrectly fabricated and were unsymmetrical, with the $-45^{\circ}$ ply on one half of the laminate thickness thicker than on the other half, so only a qualitative comparison can be made. 


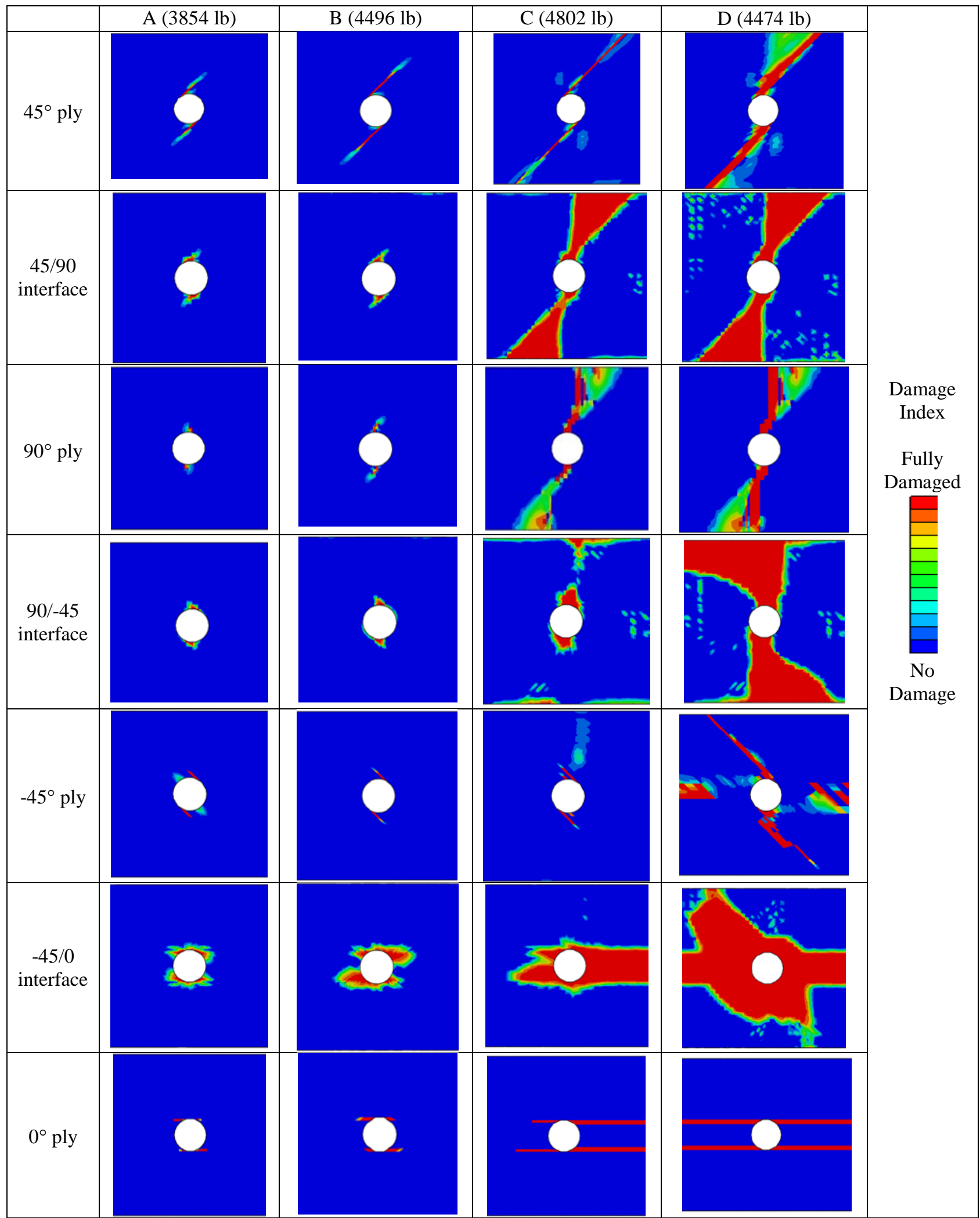

Figure 11. Damage evolution predictions obtained with the aligned mesh, $d=1 / 8$ inch, $m=4$. 
Loading direction

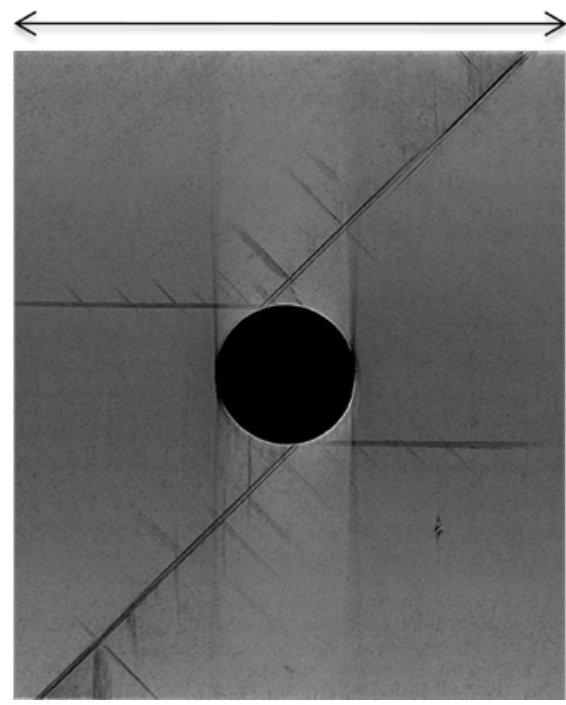

(a) X-Ray/CT, matrix cracks

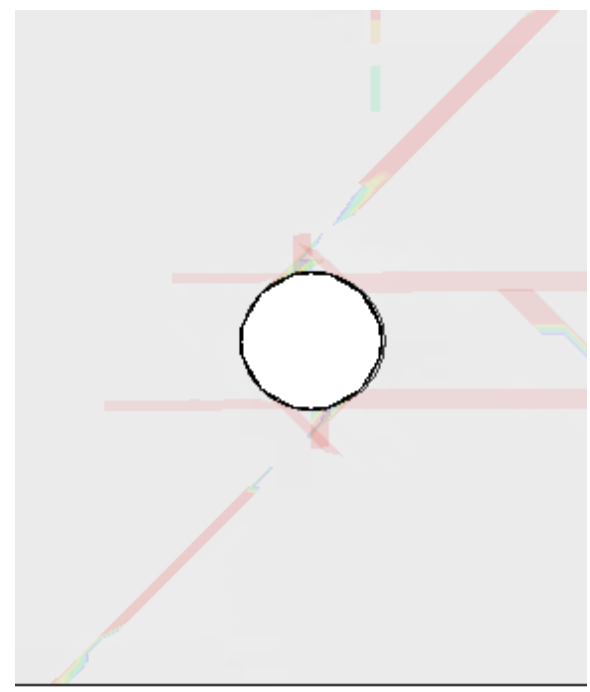

(c) Matrix crack predictions, all plies

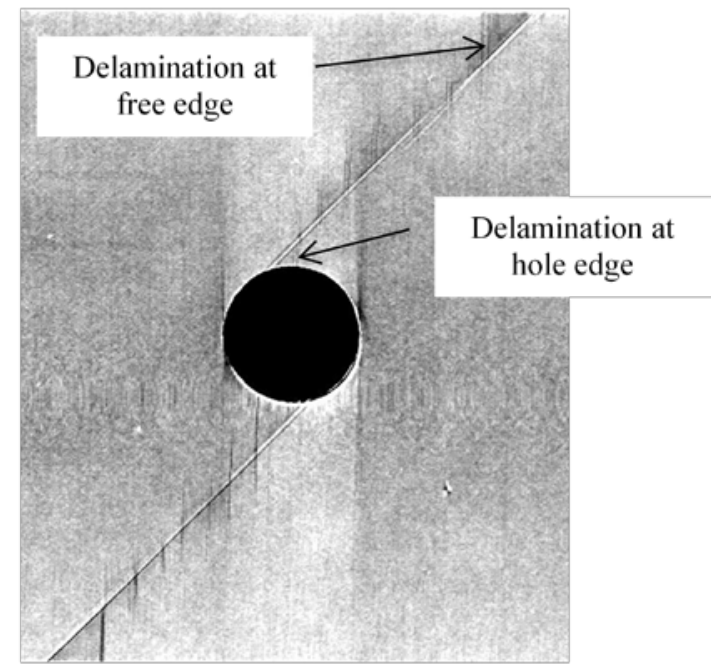

(b) X-Ray/CT, delaminations at 45/90 interface

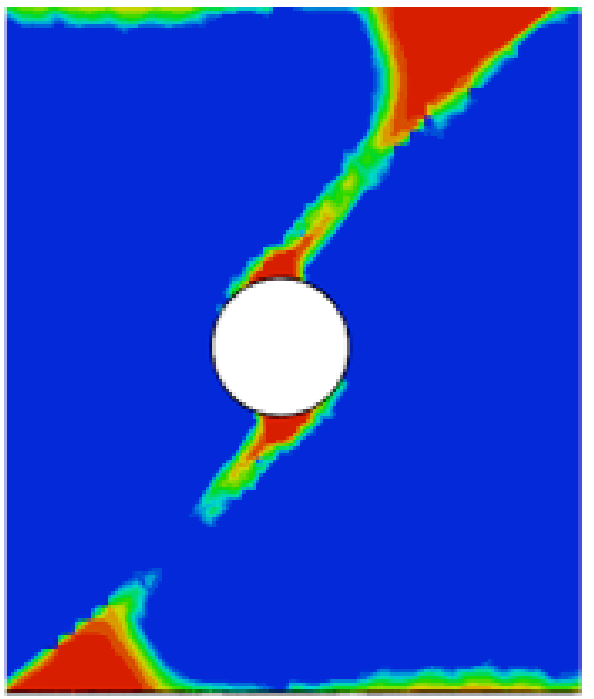

(d) Predicted delaminations at 45/90 interface

\section{Figure 12. Experimental damage and damage predictions near peak experimental load and peak numerical load, $d=1 / 8$ inch, $m=4$.}

In Fig. 12, predictions obtained near the predicted failure load are compared with NDE images of a test specimen interrupted at 95\% of the experimentally observed failure load. The results shown in Fig. 12 indicate that the analysis predicts well the delamination pattern at the 45/90 interface. Additionally, the predicted matrix crack pattern captures the dominant cracks in the $45^{\circ}$ surface ply, and the dominant axial splits. The axial splits observed in the tests develop asymmetrically around the hole, where the asymmetry in the splits is not accurately captured in the simulations. The experimental results show distributed matrix cracks in the $-45^{\circ}$ ply developing along the splits in the $45^{\circ}$ and $0^{\circ}$ plies as well as distributed matrix cracks in the $90^{\circ}$ ply along the splits in the $45^{\circ}$ ply, where the analysis predicts only a few cracks in these plies. In Fig. 13, X-Ray/CT images that were obtained just after the peak load are compared with the analysis predictions at a similar point in the load history. The analysis predictions agree well with the experimental delamination shapes at the 45/90 and 90/-45 interface. However, the delamination at the - 


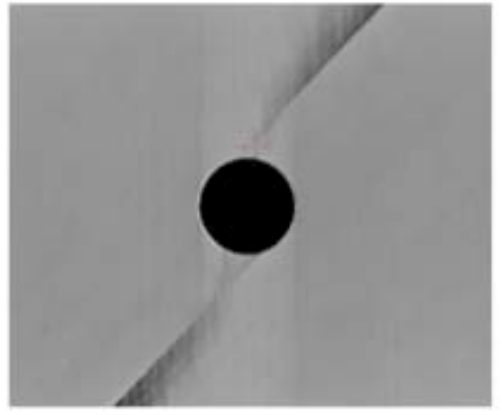

(a) $45 / 90$ interface

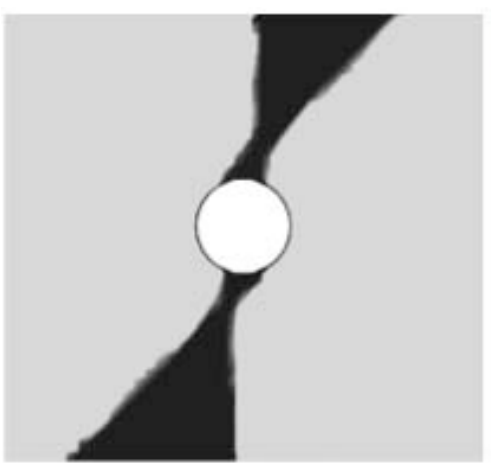

(d) $45 / 90$ interface

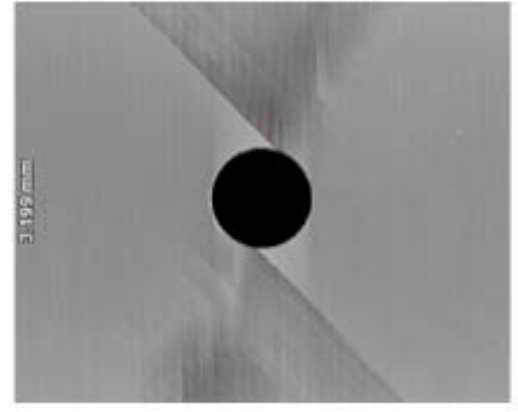

(b) $90 /-45$ interface

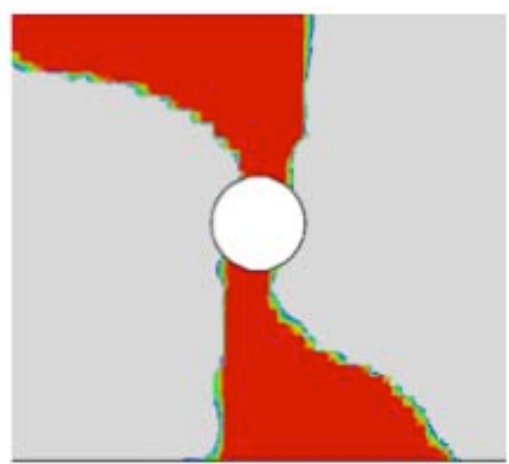

(e) 90/-45 interface

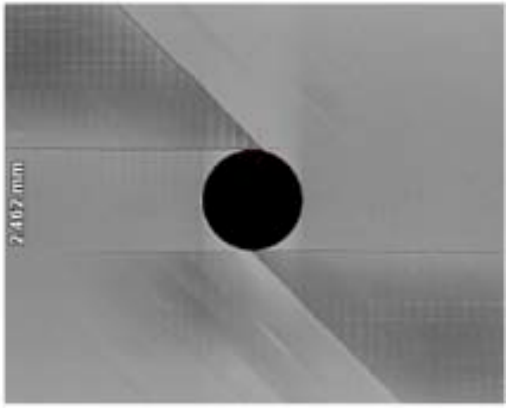

(c) $-45 / 0$ interface

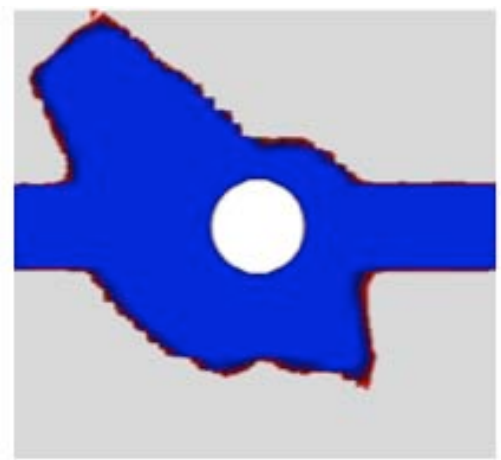

(f) $-45 / 0$ interface

Figure 13. X-Ray/CT images of delaminations at all interfaces after first load drop and predicted delaminations just beyond numerical first load drop, $d=1 / 8$ inch, $m=4$.

45/0 interface is predicted to develop both inside and outside the axial splits, while in the tests the delamination develops primarily outside the axial splits.

\section{B. In-plane and Through-Thickness Scaling Effect}

Analysis predictions obtained with the aligned mesh for studying the effect of in-plane scaling (2D scaling) and through-thickness scaling (1D scaling) for ply-level thickness scaled specimens are summarized and compared with experimental data in Table 5. For the specimen configurations considered, delamination and pull-out failure modes were observed in the tests. In the data presented, a load drop of $5 \%$ on the load-displacement curve is taken to represent specimen failure. Stress values are presented and are obtained by dividing the failure loads by the unnotched cross-sectional area. The results provided in the table indicate that the analysis generally predicts the proper failure mode. Additionally, the predicted sequence of damage development and interaction of subcritical damage and fiber failure agrees qualitatively with the experimental observations. Damage evolution results shown previously for the specimen configuration with a 1/8-inch diameter hole, and $m=4$ are representative of the predictions of the delamination failure mode for all such failure cases, consisting of significant matrix damage, delaminations between all plies, extensive delamination at the $-45 / 0$ interface, and no fiber failure. For specimens that were predicted to fail in the pull-out failure mode, damage development is characterized by significant subcritical matrix damage in all plies, delamination at all ply interfaces, and fiber failure in the $0^{\circ}$ ply. For equal inplane dimensions, and reduced values of ply thickness (reduced value of $m$ ), the extent of delamination at the $-45 / 0$ interface is reduced and fiber failure in the $0^{\circ}$ ply is more extensive. This is illustrated in Fig. 14 which compares damage predictions in the $-45 / 0$ interface and in the $0^{\circ}$ ply for laminates with a $1 / 8$-inch diameter hole, that failed in the pull-out failure mode, $m=1$, and in the delamination failure mode, $m=4$. 
Table 5. Test [20],Analysis Failure Stress (ksi) and Failure Mode Comparison for Open-HoleTension of $\left(45_{m} / 90_{m} /-45_{m} / 0_{m}\right)_{s}$ Laminates

\begin{tabular}{ccccc}
\hline \hline $\begin{array}{c}\text { Laminate } \\
\text { Thickness, } \boldsymbol{m}\end{array}$ & $\begin{array}{c}\text { Hole } \\
\text { Diameter (in) }\end{array}$ & $1 / 8$ & $1 / 4$ & $1 / 2$ \\
\hline 1 & Test & 82.7 & & \\
& Analysis & 64.1 & 50 & \\
\hline 2 & Test & 57.4 & 72.2 & \\
\hline \multirow{2}{*}{4} & Analysis & 50.6 & 49.1 & 52.5 \\
& Test & 39.9 & 41.3 & 67.5 \\
\hline \hline & Analysis & 49.5 & 56.1 & \\
& & & & \\
& Pull-out & & Delamination &
\end{tabular}

Comparison of the experimental results and the numerical predictions studying the effect of scaling on the failure load for specimen configurations with $m=4$, and for specimen configurations with $d=1 / 8$-inch is also provided in Figs. 15a and 15b, respectively. The analyses conducted with the aligned mesh consistently predict the delamination failure mode for specimen configurations having $m=4$. For these specimens the so-called inverse hole-size effect observed in the tests is predicted, as shown in Fig. 15a. The failure loads are, however, consistently over predicted. Experimental results for the specimens with a 1/8-inch diameter hole and scaled in the thickness direction indicate a decrease in failure load with increase in ply thickness, as shown in Fig. 15b. Additionally the specimen with $m=1$ failed in the pullout failure mode, and the specimens with $m=2$, 4 failed in the delamination failure mode. The analyses predicted failure in the pull-out failure mode for specimens with $m=1,2$, and in the delamination failure mode for the specimen with $m=4$. The failure loads for specimens exhibiting the pull-out failure are consistently under-predicted.
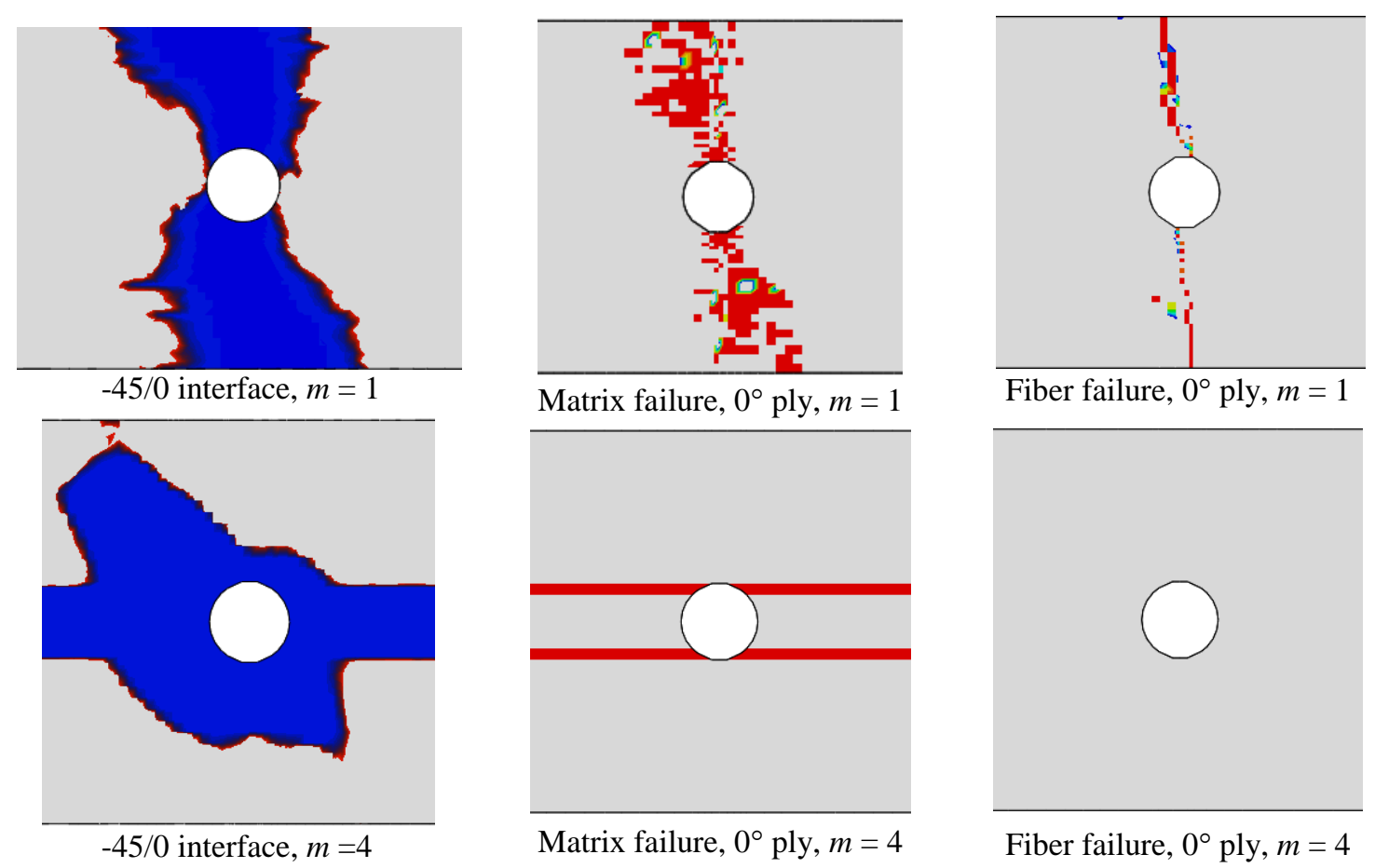

Fiber failure, $0^{\circ}$ ply, $m=4$

Figure 14. Damage predictions obtained with the aligned mesh at a point just beyond peak load, $d=$ $1 / 8$ inch, $m=1$ and 4 . 


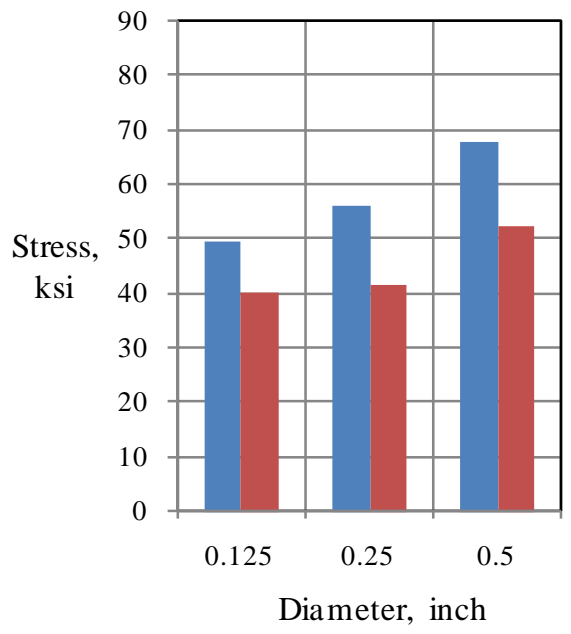

(a) In-plane scaling, for thickness $m=4$

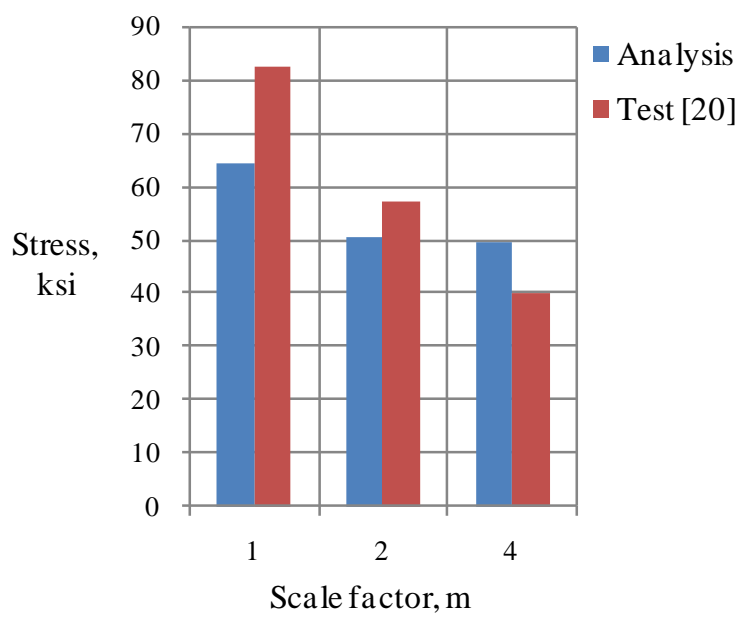

(b) Through-thickness scaling, $d=1 / 8$ inch

Figure 15. Experimentally observed and predicted effect of in-plane scaling and through-thickness scaling on failure stress.

The critical event in determining the failure stress for the delamination failure mode is the point at which the surface matrix crack propagates to the laminate free edge, and the delaminations in the 45/90 interface at the hole edge and at the free edge link-up. In all of the analysis predictions, this event is delayed compared to the test results. One possible cause for the over-prediction of the failure stress is insufficient mesh refinement. Additional study is required to determine the effect of mesh refinement on the analysis predictions. Another possible explanation for the over-prediction can be obtained by comparing the experimentally determined crack patterns, just prior to the load drop, and the predicted crack patterns. The X-Ray/CT data provided in Fig. 12, shows multiple distributed cracks in the $90^{\circ}$ ply along the split in the surface $45^{\circ}$ ply, where the analysis predicts development of a single crack in the $90^{\circ}$ ply. The multiple cracks observed experimentally in the $90^{\circ}$ ply may facilitate development of the delaminations at the 45/90 interface, and result in link-up of damage at the hole edge and at the free edge at a load lower than predicted. Additionally, thermal residual stresses from the curing process were not included in the analysis and may result in predicted late onset of matrix cracking and the accompanying delamination. A delayed onset and propagation of the sub-critical matrix and delamination damage in the analysis may also explain the underprediction of the failure loads for the specimens that failed in the pull-out failure mode. In this case, the sub-critical damage reduces the stress concentration at the hole edge and therefore delays the onset of fiber failure observed in test.

\section{Concluding Remarks}

The present paper presents a study on the performance of a state-of-the-art continuum damage mechanics (CDM) model for intralaminar damage, coupled with cohesive elements for interlaminar damage for failure simulation of quasi-isotropic open-hole tension specimens. Limitations of the CDM models are discussed with an emphasis on the influence of element orientation on the analysis predictions. Results of these studies indicate that reliable prediction of matrix crack paths and stress relaxation after cracking requires a mesh with element edges aligned with the crack direction. Based on the findings of this study, a modeling approach is proposed for the analysis of the open-hole tension specimens that consists of different meshes within the individual plies, such that the element edges are aligned with the ply fiber direction, and cohesive element layers embedded between plies. Then, tie constraints are used to connect the individual ply meshes with the cohesive element layers.

A typical radial mesh, commonly used for the analysis of open-hole specimens, and the proposed aligned mesh are used in an explicit analysis to simulate progressive intralaminar and interlaminar damage, and ultimate failure of the quasi-isotropic open-hole tension specimens. Numerical predictions are compared with experimental data ${ }^{20,21}$ to assess the modeling approach for predicting sub-critical damage development, and the ultimate failure mode and 
failure load. In the tests, three failure modes were observed for different specimen configurations: brittle, pull-out and delamination. The pull-out and delamination failure modes are considered in the present paper. The pull-out failure mode is characterized by matrix cracking in all off-axis plies, limited delamination between plies, and fiberfailure in the $0^{\circ}$ plies. The delamination failure mode is characterized by matrix cracking in all off-axis plies and extensive delamination between plies. Comparison of the numerical predictions obtained using the radial mesh with the experimental data for a specimen configuration exhibiting the delamination failure mode indicates that the radial mesh fails to predict the delamination failure mode and the ultimate failure is predicted to occur early. The delamination failure mode is, however, successfully predicted with the proposed aligned mesh, and the predicted damage evolution qualitatively agrees with the experimentally observed damage evolution. The aligned mesh model is used further to simulate the affect of in-plane (2D) and through-thickness (1D) scaling on the failure mechanism and failure load. For the specimen configurations considered, the numerical models generally predict the proper failure mechanism and the proper trends in the failure load. The failure loads for specimens exhibiting the delamination failure load are, however, consistently over predicted, and the failure loads for specimens exhibiting the pull-out failure mode are consistently under-predicted. The discrepancy in strength prediction is attributed to predicted late onset and propagation of sub-critical damage. In the case of the delamination failure mode, late onset of damage results in delayed link-up of damage through the laminate width compared to the experimental results and over-prediction of the laminate strength. In the case of the pull-out failure mode, late onset and development of subcritical damage in the analysis which results in limited reduction of the stress concentration at the hole edge, and early onset of fiber failure.

\section{References}

${ }^{1}$ Whitney, J. M., and Nuismer, R. J., "Stress Fracture Criteria for Laminated Composites Containing Stress Concentrations," Journal of Composite Materials, Vol. 8, 1974, pp. 253-265.

${ }^{2}$ Waddoups, M. E., Eisenmann, J. R., and Kaminski, B. E., "Macroscopic Fracture Mechanics of Advanced Composite Materials,” Journal of Composite Materials, Vol. 5, 1971, pp. 446-454.

${ }^{3}$ Pipes, R. B., Wetherhold, R. C., and Gillespie, J. W., Jr., “Notched Strength of Composite Materials,” Journal of Composite Materials, Vol. 12, No. 16, 1979, pp. 1151-1155.

${ }^{4}$ Mar, J. W., and Lin, K. Y., "Fracture Mechanics Correlation for Tensile Failure of Filamentary Composites with Holes," Journal of Aircraft, Vol. 14, No. 7, 1977, pp. 703-704.

${ }^{5}$ Vaidya, R. S., and Sun, C. T., "Fracture Criterion for Notched Thin Composite Laminates," AIAA Journal, Vol. 35, No. 2, 1997, pp. 311-316.

${ }^{6}$ Poe, C. C., Jr., “A Unifying Strain Criterion for Fracture of Fibrous Composite Laminates,” Engineering Fracture Mechanics, Vol. 17, No. 2, 1983, pp. 153-171.

${ }^{7}$ Awerbuch, J., and Madhukar, M. S., "Notched Strength of Composite Laminates: Predictions and Experiments - A Review," Journal of Reinforced Plastics and Composites, Vol. 4, 1985, pp. 3-159.

${ }^{8}$ Maimí, P., Camanho, P. P., Mayugo, J. A., and Dávila, C. G., “A Continuum Damage Model for Composite Laminates: Part I - Constitutive Model,” Mechanics of Materials, Vol. 39, 2007, pp. 897-908.

${ }^{9}$ Maimí, P., Camanho, P. P., Mayugo, J. A., and Dávila, C. G., “A Continuum Damage Model for Composite Laminates: Part II - Computational Implementation and Validation,” Mechanics of Materials, Vol. 39, 2007, pp. 909-919.

${ }^{10}$ Camanho, P. P., Turon, A., Costa, J., and Dávila, C. G., "A Damage Model for the Simulation of Delamination in Advanced Composites under Variable-Mode Loading,” Mechanics of Materials, Vol. 38, No. 11, Nov. 2006, pp. 1072-89.

${ }^{11}$ Krueger, R. "The Virtual Crack Closure Technique: History Approach and Applications,” NASA/CR-2002-211628, April, 2002.

${ }^{12}$ Mabson, G., Lyle, R.D., Dopker, B., Hoyt, D.M., Baylor, J.S., and Graesser, D.L., "Fracture Interface Elements for Static and Fatigue Analysis,” in 16th International Conference on Composite Materials, Kyoto, Japan, 2007.

${ }^{13}$ van der Meer, F. P., Sluys, L. J., "Continuum Models for the Analysis of Progressive Failure in Composite Laminates," Journal of Composite Materials, Vol. 40, 2009, pp. 2131-56.

${ }^{14}$ van der Meer, F.P., Oliver, C., and Sluys, L.J., "Computational Analysis of Progressive Failure in a Notched Laminate Including Shear Nonlinearity and Fiber Failure,” Composites Science and Technology, Vol. 70, No. 4, 2010, pp. $692-700$.

${ }^{15}$ Iarve, E. V., Mollenhauer, D., and Kim, R., “Theoretical and Experimental Investigation of Stress Redistribution in Open Hole Composite Laminates Due to Damage Accumulation,” Composites Part A: Applied Science and Manufacturing, Vol. 36, 2005, pp. 163-171.

${ }^{16}$ Jirásek, M., "Modeling of Localized Damage and Fracture in Quasibrittle Materials," Continuous and Discontinuous Modeling of Cohesive-Frictional Materials, Edited, 2001, pp. 17-29.

${ }^{17}$ Jirásek, M., Zimmermann, T., “Analysis of Rotating Crack Model,” Journal of Engineering Mechanics, Vol. 124, 1998, pp. 842-851.

${ }^{18}$ Jirásek, M., and Grassl, P., "Evaluation of Directional Mesh Bias in Concrete Fracture Simulations Using Continuum Damage Models,” Engineering Fracture Mechanics, Vol. 75, No. 8, 2008, pp. 1921-1943. 
${ }^{19}$ Las, V., Zemcik, R., “Progressive Damage of Unidirectional Composite Panels,” Journal of Composite Materials, Vol. 42, 2008, pp.25-44.

${ }^{20}$ Green, B. G., Wisnom, M. R., and Hallett, S. R., “An Experimental Investigation into the Tensile Strength Scaling of Notched Composites,” Composites Part A: Applied Science and Manufacturing, Vol. 38, No. 3, 2007, pp. 867-878.

${ }^{21}$ Hallett, S. R., Green, S. B., Jiang, W.- G., and Wisnom, M. R., "An Experimental and Numerical Investigation into the Damage Mechanisms in Notched Composites,” Composites Part A: Applied Science and Manufacturing, Vol. 40, 2009, pp. 613624.

${ }^{22}$ Harris, C. E., Coats, T. W., and Glaessgen, E. H., "Experimental Verification of Computational Models for Laminated Composites," Proceedings of the Society for Experimental Mechanics Spring Conference and Exposition, Cincinnati, Ohio, June 7-9, 1999.

${ }^{23}$ Shahid, I., and Chang, F.- K., “An Accumulative Damage Model for Tensile and Shear Failures of Laminated Composite Plates,” Journal of Composite Materials, Vol. 29, 1995, pp. 926-981.

${ }^{24}$ Camanho, P. P., Maimí, P., and Dávila, C. G., "Prediction of Size Effects in Notched Laminates Using Continuum Damage Mechanics,” Composites Science and Technology, Vol. 67, No. 13, 2007, pp. 2715-2727.

${ }^{25}$ Lopes, C. S., Camanho, P. P., Gürdal, Z., Maimi, P., and Gonzalez, E. V., "Low-velocity Impact Damage on Dispersed Stacking Sequence Laminates. Part II: Numerical Simulations,” Composites Science and Technology, Vol. 69, 2009 , pp. 937-947.

${ }^{26}$ Overgaard, L. C. T., Lund, E., and Camanho, P. P., "A Methodology for the Structural Analysis of Composite Wind Turbine Blades under Geometric and Material Induced Instabilities,” Computers \& Structures, Vol. 88, 2010, pp. 1092-1109.

${ }^{27}$ Bisagni, C., Vescovini, R., and Dávila, C. G., "Assessment of the Damage Tolerance of Postbuckled Hat-Stiffened Panels Using Single-Stringer Specimens,” 51st AIAA/ASME/ASCE/AHS/ASC Structures, Structural Dynamics, and Materials Conference, 12-15 Apr. 2010, Orlando, FL, USA

${ }^{28}$ Jirásek, M., “Nonlocal Models for Damage and Fracture: Comparison of Approaches,” Int. J. Solids and Structures, Vol. 35, 1998, pp. 4133-4135.

${ }^{29}$ Bažant, Z. P., Oh, B. H., “Crack Band Theory for Fracture of Concrete,” Materials and Structures, Vol. 16, No. 3, 1983, pp. 155-77.

${ }^{30}$ Anon., ABAQUS Analysis User's Manual: Volumes I - VI, Version 6.10, Dassault Systèmes Simulia Corp., Providence, RI, 2010.

${ }^{31}$ Hashin, Z., “Failure Criteria for Unidirectional Fiber Composites,” Journal of Applied Mechanics, Vol. 47, 1980, pp. 329334.

${ }^{32}$ Catalanotti, G., Camanho, P. P., Xavier, J., Dávila, C. G., and Marques, A. T., "Measurement of Resistance Curves in the Longitudinal Failure of Composites Using Digital Image Correlation,” Composites Science and Technology, Vol. 70, 2010, pp. 1986-1993.

${ }^{33}$ Benzeggagh, M. L. and Kenane, M., "Measurement of Mixed-mode Delamination Fracture Toughness of Unidirectional Glass/epoxy Composites with Mixed-mode Bending Apparatus,” Compos. Sci. Technol., Vol. 56, No. 4, 1996, pp. $439-449$.

${ }^{34}$ Camanho, P. P., Dávila, C .G., Pinho, S. T., Iannucci, L., and Robinson, P., "Prediction of in-Situ Strengths and Matrix Cracking in Composites under Transverse Tension and in-Plane Shear,” Composites Part A: Applied Science and Manufacturing., Vol. 37, 2005, pp. 165-176. 